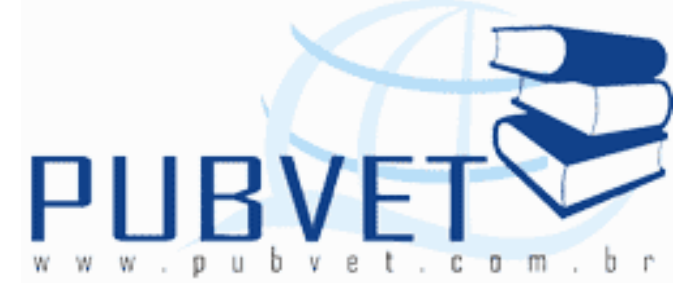

PUBVET, Publicações em Medicina Veterinária e Zootecnia.

\title{
Estudo descritivo da população rural canina da Vila Juerana, Distrito de Aritaguá, Município de Ilhéus-BA, 2012.
}

Tatiani Vitor Harvey ${ }^{1}$, Dunezeu Alves Campos Júnior ${ }^{2}$, Taís Passos Cardoso ${ }^{3}$

${ }^{1}$ Discente do curso de Medicina Veterinária da Universidade Estadual de Santa Cruz - UESC. Endereço para correspondência: Caixa Posta 383, Centro, IlhéusBahia, CEP 45653-970. tatianivitor@yahoo.com.br

${ }^{2}$ Professor Adjunto B do curso de Medicina Veterinária, Departamento de Ciências Agrárias, UESC. dunezeu2@uol.com.br

${ }^{3}$ Membro da Associação de Moradores da Vila Juerana - AMORVIJU

\section{Resumo}

Nas comunidades rurais, o cão desempenha papéis essenciais como vigia, companhia e auxiliar de caça. Freqüentemente, a falta de informação sobre o manejo adequado deste animal e a indiferença dos proprietários resulta na disseminação de zoonoses e outros agravos a saúde de ambas as espécies e ao ambiente. Com o objetivo de determinar o perfil da população canina, o perfil sócio-econômico dos proprietários de cães e de avaliar e analisar a aplicação dos princípios de guarda responsável na Vila Juerana, aplicou-se nesta comunidade, em março de 2012, um censo canino, através de um questionário semiestruturado. Os dados demonstraram a relação cão/habitante de $1: 3,7,53 \%$ de fêmeas, $79 \%$ de animais jovens, $71 \%$ de cães semidomiciliados, $71 \%$ de cães que acessavam o interior das residências, 
HARVEY, T.V., CAMPOS JÚNIOR, D.A. e CARDOSO, T.P. Estudo descritivo da população rural canina da Vila Juerana, Distrito de Aritaguá, Município de Ilhéus-BA, 2012. PUBVET, Londrina, V. 7, N. 1, Ed. 224, Art. 1485, 2013.

renda familiar de até 1 salário em 45,1\% domicílios. Os resultados demonstraram um manejo inadequado destes animais e a necessidade de aplicação de programas de controle da população canina e de programas de prevenção e controle de doenças, nesta comunidade, por parte do Serviço Público de Saúde.

Palavras-chave: Cães, Comunidades rurais, Saúde Pública, Zoonoses.

\title{
Descriptive profile of a rural canine population in Juerana Village, Aritaguá district, city of Ilhéus, Bahia, Brazil, 2012.
}

\begin{abstract}
In rural communities, dogs provide important and essential roles, such as hunters, companions and security. Often, dog owners lack sufficient knowledge of canine management or are indifferent to their dogs' well-being resulting in the spread of diseases to human, animal and the surrounding environment. A semi-structured questionnaire survey was taken, in March 2012, in order to determine the canine population profile of Juerana Village, the socio-economic profile of the dog owners and evaluate and analyze whether owners are applying the principles of responsible dog care. The data revealed the dog-to-human ratio was $1: 3,7,53 \%$ were female dogs, $79 \%$ were young dogs, $71 \%$ were semi-restricted dogs, $71 \%$ of dogs access to interior of the family house, $45,1 \%$ of the household received minimum salary or less. The results indicate that the management of the dogs was inadequate and the need for Public Health Services to implement a dog population control program and zoonotic diseases prevention and control programs in this community.
\end{abstract}

Keywords: Canine. Environment, Preventive Medicine and Public Health. Rural communities. Zoonoses. 
HARVEY, T.V., CAMPOS JÚNIOR, D.A. e CARDOSO, T.P. Estudo descritivo da população rural canina da Vila Juerana, Distrito de Aritaguá, Município de Ilhéus-BA, 2012. PUBVET, Londrina, V. 7, N. 1, Ed. 224, Art. 1485, 2013.

\section{INTRODUÇÃO}

Desde o início da sua relação com o homem, o cão assumiu um papel importante na sociedade humana, conferindo-lhes companhia, proteção, transporte, caça e serviços sociais. Para as comunidades periféricas e rurais, este animal torna-se fundamental, uma vez que nestes locais é atribuída a ele a responsabilidade da segurança da família e de seus bens, além da garantia do alimento através da caça. Porém, apesar dos benefícios mútuos desta relação, o descaso e a falta de informação a respeito do manejo destes animais coloca em risco a saúde das populações de ambas as espécies e do ambiente, fragilizando esta relação.

A procriação descontrolada aliada à despreocupação e falta de informação dos proprietários a respeito do manejo correto destes animais constituem um grave problema mundial de saúde pública, tornando-os indesejados pelos agravos que produzem às pessoas, a outros animais e ao meio ambiente ${ }^{1}$, a exemplo da transmissão de doenças, danos a propriedades públicas e privadas, poluição sonora e ambiental, mordeduras, e acidentes de trânsito ${ }^{2}$. Os agravos ambientais decorrem de hábitos precários de higiene ambiental e individual, de responsabilidade do proprietário².

Em comunidades carentes, a exemplo de áreas rurais, é freqüente a presença de doenças ectoparasitárias em humanos, como escabiose, pediculose, tungíase e larva migrans cutânea ${ }^{3}$ e doenças endoparasitárias como tricuríase e ancilostomíase ${ }^{4}$. Tais doenças podem ser veiculadas por cães.

Segundo Matos et al., 2002, a densidade de cães depende da cultura local, que estabelece padrões na interação de seres humanos com animais, do controle de mobilidade e de natalidade, e da disponibilidade de alimentos, abrigos e água, dispersos no meio ambiente 5 . Soto et al., 2006, por exemplo, encontrou a razão cão:habitante média de 1:3,16, na zona rural do Município 
HARVEY, T.V., CAMPOS JÚNIOR, D.A. e CARDOSO, T.P. Estudo descritivo da população rural canina da Vila Juerana, Distrito de Aritaguá, Município de Ilhéus-BA, 2012. PUBVET, Londrina, V. 7, N. 1, Ed. 224, Art. 1485, 2013.

de Ibiúna-SP ${ }^{6}$. Esta relação varia entre 1:3,5 a 1:16 em alguns países da África? .

O Brasil tem grandes concentrações populacionais de cães em zonas periféricas ou suburbanas ${ }^{8}$. Tais locais, normalmente, têm deficiências ou carecem de serviços de saneamento ${ }^{9}$, além de concentrarem populações humanas com baixo nível sócio econômico, vítimas potenciais de surtos epizoóticos.

O planejamento de programas de saúde envolvendo cães requer o conhecimento da densidade populacional dos animais, bem como a sua distribuição segundo estratos, definidos pelos distintos níveis de cuidados que recebem ${ }^{10}$. Além disso, é fundamental conhecer a ecologia e a biologia destes animais e das condições socioculturais e econômicas da comunidade ${ }^{6}$, além da identificação do perfil dos proprietários e seu nível de conhecimento sobre guarda responsável e zoonoses.

No Brasil, os programas de controle das populações caninas, controle de zoonoses, e de educação em saúde se baseiam nas orientações da OMS.A inexistência de um censo canino oficial no país ${ }^{11}$ reduz a eficácia de controle destes animais, uma vez que o censo é um instrumento fundamental para o controle de doenças como a raiva, em ações prioritárias como a vacinação animal e a vigilância epidemiológica das doenças ${ }^{12}$.

Todo e qualquer método utilizado para o controle de populações caninas precisa de informações quantitativas e qualitativas para seu planejamento. Censo, amostragens, questionários e registros de atividades diversas, são alguns dos métodos utilizados, sendo o censo indicado, principalmente, para pequenos municípios, regiões definidas e restritas e para a zona rural ${ }^{1}$.

Objetivou-se com este trabalho, por meio de um estudo censitário, quantificar e avaliar a estrutura da população canina, além de descrever o perfil dos proprietários de cães do povoado da Vila Juerana, Município de Ilhéus, Bahia, a fim de gerar subsídios para o desenvolvimento de programas que promovam a melhoria da qualidade de vida desta comunidade. 
HARVEY, T.V., CAMPOS JÚNIOR, D.A. e CARDOSO, T.P. Estudo descritivo da população rural canina da Vila Juerana, Distrito de Aritaguá, Município de Ilhéus-BA, 2012. PUBVET, Londrina, V. 7, N. 1, Ed. 224, Art. 1485, 2013.

\section{MATERIAL E MÉTODOS}

\section{Local de estudo}

O povoado da Vila Juerana situa-se no distrito de Aritaguá, ao norte da zona urbana do Município de Ilhéus, estado da Bahia, na BA-001, trecho Ilhéus-Itacaré, $\mathrm{Km} 10$ (S $14.96767^{\circ}$, W 039.32436). Segundo a Associação de Moradores do local, a população estimada é de 800 habitantes e de aproximadamente 300 residências. Situa-se à margem esquerda do Rio Almada, dentro de uma área de transição entre a restinga e a Mata Atlântica, pertencente à área de abrangência ou influência da Área de Proteção Ambiental (APA) da Lagoa Encantada.

\section{Considerações Éticas}

Este trabalho foi analisado e aprovado pelo Comitê de Ética em Pesquisa em Seres Humanos, da Universidade Estadual de Santa Cruz, através do Parecer Consubstanciado n.734. Todas as etapas deste projeto foram acompanhadas por um membro da Associação de Moradores da Vila Juerana.

\section{Coleta de dados}

Em março de 2012 foi realizado um inquérito canino domiciliar, em área central da comunidade da Vila Juerana, através de um questionário semiestruturado ${ }^{13}$, no qual foram abordados aspectos gerais e aspectos relacionados ao manejo sanitário e reprodutivo dos cães, além do perfil sócioeconômico-cultural do proprietário e noções sobre zoonoses e guarda responsável. Uma vez que todos os moradores da vila estavam direta ou indiretamente expostos ao risco da transmissão de zoonoses, foi adotado como critério de inclusão que todas as residências fossem pesquisadas, sendo que qualquer morador adulto ou jovem a partir dos 16 anos, com consentimento do adulto responsável, poderia responder ao questionário. Foi dada preferência a entrevista com o morador responsável pelos cuidados com o(s) animal( is). 
HARVEY, T.V., CAMPOS JÚNIOR, D.A. e CARDOSO, T.P. Estudo descritivo da população rural canina da Vila Juerana, Distrito de Aritaguá, Município de Ilhéus-BA, 2012. PUBVET, Londrina, V. 7, N. 1, Ed. 224, Art. 1485, 2013.

Durante a interpelação, os termos desconhecidos foram esclarecidos, respeitando-se o nível cultural da cada entrevistado. $\mathrm{Na}$ análise dos dados os cães foram classificados segundo a orientação da OMS, na publicação Guidelines for dog population management (1990):

a) Cães domiciliados: animal com proprietário, totalmente dependente e totalmente controlado.

b) Cães semidomiciliados: animal com proprietário, totalmente dependente e parcialmente controlado. Neste grupo, também foram incluídos os cães que ficavam presos, mas a passeio com seus proprietários ficavam sem controle.

\section{Análise dos dados}

Os percentuais de ocorrência das variáveis foram tabelados em planilhas do Excel e exibidos em formas de tabelas e gráficos.

\section{RESULTADOS E DISCUSSÃO}

Das 104 residências da área de estudo, 85,5\% (89) foram interpeladas, como pode ser observado na Tabela 1.

Tabela 1. População canina e humana da área de estudo da Vila Juerana. Ilhéus-BA. 2012.

\begin{tabular}{|c|c|c|c|c|c|c|}
\hline \multicolumn{4}{|c|}{ Proprietárias entrevistados } & Número & Número & \\
\hline $\begin{array}{l}\text { Com } \\
\text { cão }\end{array}$ & $\begin{array}{c}\text { Ocorrência } \\
(\%)\end{array}$ & $\begin{array}{l}\text { Sem } \\
\text { cão }\end{array}$ & $\begin{array}{c}\text { Ocorrência } \\
(\%)\end{array}$ & \multirow{3}{*}{100} & \multirow{3}{*}{368} & \multirow{3}{*}{$1: 3,7$} \\
\hline 54 & 60,6 & 35 & 39,3 & & & \\
\hline \multicolumn{4}{|c|}{ Total: $\mathbf{8 9}$} & & & \\
\hline
\end{tabular}

Os resultados referentes à dinâmica populacional (razão cão:habitante, população, faixa etária, gênero, raça) estão apresentados nas Tabelas 1 e 2 . 
HARVEY, T.V., CAMPOS JÚNIOR, D.A. e CARDOSO, T.P. Estudo descritivo da população rural canina da Vila Juerana, Distrito de Aritaguá, Município de Ilhéus-BA, 2012. PUBVET, Londrina, V. 7, N. 1, Ed. 224, Art. 1485, 2013.

Como pode ser observado na Tabela 1, 60,6 \% dos interpelados possuíam 1 ou mais cães. A presença de cães por domicilio variou de 1 a 6 cães, sendo que a razão cão:domicilio foi de 1,12. Domingos et al., 2007 encontraram a razão média cão:domicílio de 1,2, no Município de Campo Grande, MS $^{14}$. Magnabosco, 2006, observou razão aproximada de 1,43, no Município de São Paulo, $2003^{8}$. Neste estudo, a maioria dos proprietários $(53,7 \%)$ possuía mais de um cão. Destes, 33,3\% e 14,8\%, possuíam dois e três cães, respectivamente. Salienta-se que a maioria dos domicílios que possuíam mais que dois animais, apresentaram em condições sócioeconômicas e higiênicas precárias.

A razão cão:habitante no período, nesta área, foi $1: 3,7$, ou seja, a população canina correspondeu a $27,1 \%$ da população humana. A OMS, 1992, preconizou a razão cão:habitante de $1: 8$, ou seja, $12,5 \%$ da população humana, para países emergentes ${ }^{15}$, porém estudos em diversos países demonstram uma alta variabilidade nesta relação, a exemplo da relação 1:16 observada no Sri Lanka ${ }^{16}, 1: 7,28$, em São Paulo ${ }^{8}$ e 1:2,6, num bairro do Município de Jabuticabal, em São Paulo ${ }^{17}$.

Em 1990 a OMS afirmou, ainda, que a razão cão:habitante, geralmente é mais elevada nas zonas rurais. No Brasil, a razão cão:habitante em 1:8 foi preconizada pelo Ministério da Saúde, em $2002^{18}$. A relação observada neste estudo corrobora trabalhos como o de Butler e Bingham, 2000, que observaram esta taxa em 1:3,5, em área rural da Tunísia ${ }^{16}$ e de Mascarenhas et al., 2009, que num estudo com a população canina do Município de Lauro de Freitas-BA, observou maior relação cão:habitante no Distrito rural de Areia Branca (1:3), caracterizado pelos menores índices sócio-econômicos do município ${ }^{12}$. A relação elevada nestes estudos, pode estar relacionada com as características sócio-culturais destas localidades. Assim como no estudo de Mascarenhas et al., na Vila Juerana predomina o tipo de moradia horizontal, onde os cães são criados com finalidade de guarda, caça e companhia. Soto et al., 2006, observou um aumento na razão média cão:habitante $(1: 3,16)$, num 
HARVEY, T.V., CAMPOS JÚNIOR, D.A. e CARDOSO, T.P. Estudo descritivo da população rural canina da Vila Juerana, Distrito de Aritaguá, Município de Ilhéus-BA, 2012. PUBVET, Londrina, V. 7, N. 1, Ed. 224, Art. 1485, 2013.

estudo sobre a população canina domiciliada, que abrangeu 46 bairros rurais do Município de Ibiúna-SP, no período de 1998 a 2002, provavelmente pela busca de segurança nos domicílios ${ }^{6}$.

Tabela 2 - Perfil dos cães domiciliados e semidomiciliados da Vila Juerana. Ilhéus-BA. 2012.

\begin{tabular}{|c|c|c|c|c|c|}
\hline \multirow{2}{*}{\multicolumn{2}{|c|}{ Perfil }} & \multicolumn{2}{|c|}{ Domiciliados } & \multicolumn{2}{|c|}{ Semidomiciliados } \\
\hline & & $\begin{array}{c}\text { № de } \\
\text { animais }\end{array}$ & $(\%)$ & $\begin{array}{c}\text { № de } \\
\text { animais }\end{array}$ & $(\%)$ \\
\hline № de animai & & 8 & 8 & 92 & 92,0 \\
\hline Sexo & $\begin{array}{l}M \\
F\end{array}$ & $\begin{array}{l}5 \\
3\end{array}$ & $\begin{array}{l}62,5 \\
37,5\end{array}$ & $\begin{array}{l}42 \\
50\end{array}$ & $\begin{array}{l}45,6 \\
54,3\end{array}$ \\
\hline Faixa etária & $\begin{array}{l}<1 \text { ano } \\
1-4 \text { anos } \\
>4 \text { anos }\end{array}$ & $\begin{array}{l}1 \\
4 \\
3\end{array}$ & $\begin{array}{c}12,5 \\
50 \\
37,5\end{array}$ & $\begin{array}{l}32 \\
42 \\
17\end{array}$ & $\begin{array}{l}34,7 \\
45,6 \\
18,4\end{array}$ \\
\hline $\begin{array}{l}\text { Raça } \\
\text { SRD }\end{array}$ & & $\begin{array}{l}4 \\
4\end{array}$ & $\begin{array}{l}50 \\
50\end{array}$ & $\begin{array}{c}5 \\
87\end{array}$ & $\begin{array}{r}5,4 \\
94,5\end{array}$ \\
\hline $\begin{array}{l}\text { Acesso ao } \\
\text { interior da } \\
\text { casa }\end{array}$ & & 4 & 50 & 67 & 72,8 \\
\hline Função & $\begin{array}{l}\text { Companhia } \\
\text { Vigia }\end{array}$ & $\begin{array}{l}4 \\
4\end{array}$ & $\begin{array}{l}50 \\
50\end{array}$ & $\begin{array}{l}58 \\
46\end{array}$ & $\begin{array}{l}63,0 \\
50,0\end{array}$ \\
\hline
\end{tabular}

Na Tabela 2, observa-se o predomínio de cães semidomiciliados. Essa característica pode ser um reflexo do perfil da população local, uma vez que, conforme relatos de moradores, o cão livre tem a chance de encontrar alimento em outros locais da Vila e também de prover segurança aos moradores da comunidade. Tal testemunho denota a falta de conhecimento a respeito da transmissão de zoonoses e o descaso com a possibilidade de ocorrência de agravos como a mordedura, não apenas para a população local, mas para a população de fora que freqüenta a Vila. Geffrey e Paris, 2001, afirmaram que a mordedura e a arranhadura são vias de transmissão de zoonoses importantes ${ }^{19}$. A mordida de um cão veicula bactérias como Pasteurella multocida, Staphylococcus, Streptococcus e anaeróbicos ${ }^{20}$. Salienta-se que, na maioria dos imóveis os quintais eram abertos, o que 
HARVEY, T.V., CAMPOS JÚNIOR, D.A. e CARDOSO, T.P. Estudo descritivo da população rural canina da Vila Juerana, Distrito de Aritaguá, Município de Ilhéus-BA, 2012. PUBVET, Londrina, V. 7, N. 1, Ed. 224, Art. 1485, 2013.

facilitava o acesso dos cães à Vila, potencializando a ocorrência de mordeduras.

Neste contexto, $44,4 \%$ dos proprietários afirmaram já terem sido mordidos. Destes, apenas 29,1\% procuraram ajuda médica e receberam a vacina de profilaxia pós-exposição. Vários fatores podem estar relacionados com esta ocorrência, a exemplo do distanciamento da Vila Juerana dos pontos de saúde do município e o descaso com a doença. Ressalta-se que, todos os moradores que não procuraram auxílio médico tinham conhecimento sobre o risco de transmissão de raiva. Burki, 2008, relatou que, na Índia, três em cinco pessoas mordidas por cães não procuram atendimento médico, provavelmente por ignorância ${ }^{21}$. Salienta-se que $49,4 \%$ dos proprietários entrevistados não possuíam o ensino fundamental completo.

Dos quintais dos proprietários de cães domiciliados, apenas um era aberto e, neste domicílio, os cães viviam com o dono dentro de casa, sendo que quando acessavam o quintal eram mantidos presos. Segundo Vieira et al., 2006, "a falta de supervisão e a mobilidade errática constituem riscos à saúde dos animais, que podem passar a integrar o grupo de reservatórios de doenças para seres humanos e para outros animais da mesma ou de espécies diferentes" ${ }^{\prime 2}$.

Quanto a distribuição por gênero, 53\% dos animais eram fêmeas e, destas $94,3 \%$ eram semidomiciliadas. Este dado, provavelmente, indica uma ausência de preferência por qualquer dos gêneros e, provavelmente, uma despreocupação por parte dos proprietários de fêmeas domiciliadas com a geração de filhotes e problemas relacionados ao cio das cadelas. Todas as fêmeas domiciliadas eram controladas, sendo uma isolada quando em cio, uma recebia anticoncepcional e uma castrada. Das fêmeas semidomiciliadas $72 \%$ não eram recebiam controle reprodutivo, apenas $10 \%$ eram isoladas no cio e $18 \%$ recebiam anticoncepcionais. O elevado número de fêmeas, em sua maioria sem controle reprodutivo, perpetua o crescimento populacional descontrolado da espécie dentro desta comunidade. Segundo Thornton, 1992, 
HARVEY, T.V., CAMPOS JÚNIOR, D.A. e CARDOSO, T.P. Estudo descritivo da população rural canina da Vila Juerana, Distrito de Aritaguá, Município de Ilhéus-BA, 2012. PUBVET, Londrina, V. 7, N. 1, Ed. 224, Art. 1485, 2013.

uma só cadela pode originar, direta ou indiretamente, 67.000 cães, num período de seis anos ${ }^{22}$, em condições ótimas de manejo.

Este resultado também indicaria uma despreocupação com os problemas relacionados ao cio. Porém, o cio foi indicado como uma das situações mais incômodas proporcionadas por estes animais, pela maioria dos proprietários que reclamaram do alto número de cães vagando pelas ruas da Vila. Vale ressaltar que, ao serem indagados sobre a importância do controle reprodutivo dos animais, $89,8 \%$ dos proprietários indicaram a importância do controle, 5,6\% consideraram não ser importante e 4,4\% disseram não saber.

Em relação às ninhadas de filhotes, estes, segundo relatos, eram distribuídos entre os moradores locais. Tal fato revela a possibilidade de uma elevada taxa de consangüinidade entre os cães nativos. A mortalidade dos recém-nascidos foi relatada como freqüente.

$\mathrm{Na}$ distribuição da população canina segundo a faixa etária (Tabela 2) observou-se que a população era composta, em sua maioria, por animais jovens $33 \%$ menores de um ano, $46 \%$ entre um a quatro anos e $20 \%$ de cães maiores de quatro anos. Estes percentuais revelaram uma população com alto índice de crescimento, o que configura uma pirâmide populacional de base alta. A população canina domiciliada caracterizou-se por um grupo de cães menores de um ano 2,7 vezes menor que o mesmo grupo da população canina semidomiciliada e, por um grupo de cães maiores de quatro anos, duas vezes maior que o seu correspondente na população semidomiciliada.

A inversão populacional dos extremos etários (Figura 1) pode estar relacionada com o tipo de manejo a qual estes animais eram submetidos. A expectativa de vida dos cães domiciliados foi maior. A justificativa desta característica, após uma análise do tipo de manejo sanitário e alimentar oferecido, poderia ser o fornecimento de alimentação de melhor qualidade, como ração, por $71,4 \%$ dos proprietários dos cães domiciliados, opostamente ao fornecimento de resíduos de comida caseira e oferta de ração por $53,7 \%$ dos proprietários dos cães semidomiciliados. Ressalta-se que, conforme 
HARVEY, T.V., CAMPOS JÚNIOR, D.A. e CARDOSO, T.P. Estudo descritivo da população rural canina da Vila Juerana, Distrito de Aritaguá, Município de Ilhéus-BA, 2012. PUBVET, Londrina, V. 7, N. 1, Ed. 224, Art. 1485, 2013.

relatos, em relação à alimentação mista oferecida, a maior parte da composição era de sobras alimentares humanas. Outra justificativa seria o nível de restrição de mobilidade a qual estes animais eram expostos, uma vez que, na condição domiciliada a exposição a uma maior diversidade de patógenos, brigas entre cães, acidentes e maus tratos, seria menor. Salientase ainda, que os cães domiciliados, durante o inquérito, apresentaram, visualmente, melhor condição clínica.

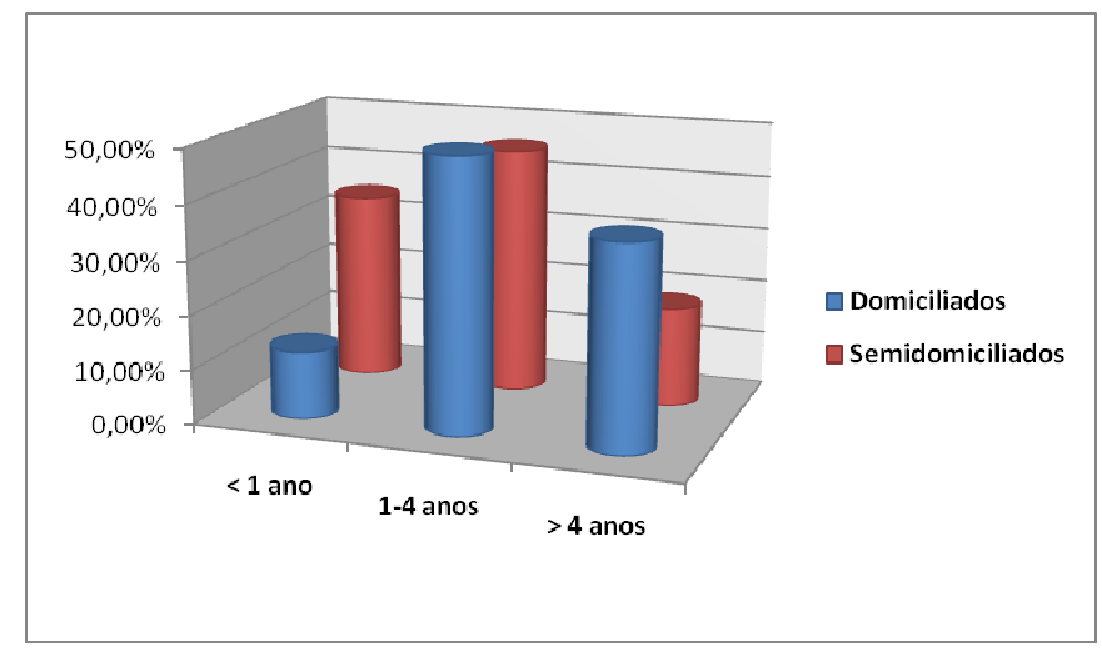

Figura 1 - Perfil etário da população canina da Vila Juerana. Ilhéus-BA. Março. 2012.

O número menor de animais domiciliados com menos de um ano pode dever-se ao menor número de fêmeas, considerando que, das três exemplares, uma era castrada e uma era isolada, quando em cio.

Em contrapartida, o número elevado de animais semidomiciliados com menos que um ano e menor número de cães semidomiciliados maiores de quatro anos, pode dever-se a seu baixo nível de restrição de mobilidade, o que potencializaria a exposição destes animais a uma alta diversidade de agravos a sua saúde, culminando em mortalidade precoce e cópula descontrolada, favorecendo o crescimento populacional, uma vez que, na condição semidomiciliada, 54,3 \% são fêmeas.

O alto número de animais domiciliados (50\%) e semidomiciliados $(45,6 \%)$ com idades entre um e quatro anos é outro fator que pode contribuir 
HARVEY, T.V., CAMPOS JÚNIOR, D.A. e CARDOSO, T.P. Estudo descritivo da população rural canina da Vila Juerana, Distrito de Aritaguá, Município de Ilhéus-BA, 2012. PUBVET, Londrina, V. 7, N. 1, Ed. 224, Art. 1485, 2013.

para a expansão da população canina, por ser esta a idade de maior fertilidade.

As populações caninas domiciliadas e semidomiciliadas, raceadas, apresentaram-se em 50\% e 5,4\%, respectivamente. Os cães raceados observados durante o inquérito apresentaram condição clínica satisfatória à inspeção visual, opostamente aos cães semidomiciliados, o que pode indicar que os cães domiciliados recebiam um melhor manejo nutricional e sanitário.

O acesso ao interior da residência (71\%) apresentou-se comum para a grande maioria dos cães, como pode observar-se na Tabela 2, embora inúmeros animais cumprissem a função de guarda que, normalmente fixa o animal aos quintais das residências. Dos cães domiciliados raceados, apenas um tinha acesso a casa, e despenhava a função de companhia. Os outros desempenhavam a função de guarda e eram mantidos apenas nos quintais. Dos domiciliados SRD, apenas um, mestiço de Pastor Alemão, era utilizado para guarda. Tais dados indicam a preferência dos proprietários em criar cães domiciliados raceados para desempenhar o papel de guarda.

Em relação aos cães semidomiciliados, observou-se que a maioria desempenhava as funções de companhia e vigia. Considerando o número de cães que acessavam o interior da residência, pode-se supor que o fato de os cães desempenharem o papel de companhia, viabiliza seu acesso ao interior das residências, potencializando o risco de transmissão de doenças e agravos à família.

Em relação ao manejo sanitário dos cães da Vila Juerana, observou-se que o único cuidado sanitário efetuado por $100 \%$ dos proprietários foi o banho, porém este era dado no rio, por grande parte dos moradores. Tal fato viabiliza a disseminação de doenças veiculadas pela água, nesta localidade. Dos cães domiciliados, $87,5 \%$ estavam infestados por pulgas e 75\% por carrapatos. Dos cães semidomiciliados, 89,1\% estavam infestados por pulgas e 79,3 por carrapatos. O tratamento com pulgicidas e carrapaticidas era feito 
HARVEY, T.V., CAMPOS JÚNIOR, D.A. e CARDOSO, T.P. Estudo descritivo da população rural canina da Vila Juerana, Distrito de Aritaguá, Município de Ilhéus-BA, 2012. PUBVET, Londrina, V. 7, N. 1, Ed. 224, Art. 1485, 2013.

em 100 e 98,9\% dos cães domiciliados e semidomiciliados, respectivamente. Alguns proprietários optavam por catar seus animais.

Fatores como a composição arenosa das ruas, o predomínio de moradias horizontais, com grande número de barracos e casas de madeira, o recolhimento inadequado do lixo e a presença de diferentes espécies animais transitando pelas ruas locais, além da presença da fauna sinantrópica, favorecem a proliferação destes ectoparasitos na comunidade. A presença desses agentes potencializa o risco de transmissão de doenças ao seres humanos, a exemplo de erliquiose e Doença de Lyme, transmitida por carrapato e a peste, transmitida por pulgas infectadas ${ }^{23}$.

Em relação ao controle parasitológico dos cães, dos cães domiciliados $50 \%$ recebiam vermifugação regular e os outros $50 \%$ não a recebiam com regularidade. Dos cães semidomiciliados 42,4 recebiam vermifugação regular, $30,4 \%$ recebiam vermifugação irregular e $27,1 \%$ não eram vermifugados. A partir destes dados pode-se supor que o risco potencial de transmissão de zoonoses parasitárias na Vila Juerana é alto, uma vez a maioria da população canina é jovem e não é submetida a um controle parasitário adequado. Alguns proprietários informaram dar antihelmíntico humano aos seus cães, enquanto outros os vermifugavam apenas quando estes se encontravam doentes ou alimentando-se mal.

Vale ressaltar que $74 \%$ dos proprietários informaram já terem sido acometidos por parasitoses e relataram inúmeros casos de bicho geográfico, a Larva Migrans Cutânea (LMC), nesta localidade. Uma interpelada, não proprietária de cão, relatou um caso de LMC num de seus filhos.

Em relação a remoção de fezes do ambiente, esta era realizada pela grande maioria dos proprietários, porém, apenas ao redor das residências, provavelmente pela inconveniência do odor. Alguns proprietários alegaram que seus cães não costumavam defecar perto da residência, e se dirigiam a outras áreas para fazê-lo. Considerando o inadequado controle de parasitas nos cães e os relatos sobre infecções parasitárias nos moradores locais, 
HARVEY, T.V., CAMPOS JÚNIOR, D.A. e CARDOSO, T.P. Estudo descritivo da população rural canina da Vila Juerana, Distrito de Aritaguá, Município de Ilhéus-BA, 2012. PUBVET, Londrina, V. 7, N. 1, Ed. 224, Art. 1485, 2013.

apesar de não ter sido feita amostragem do solo, pode-se supor que este esteja, em grande parte, contaminado por parasitos. Segundo Rey, 1992, a contato direto com cães não é indispensável para que ocorra a infecção, basta que se entre em contato com o solo contaminado com excremento de cães parasitados 24 .

Em relação à vacinação dos cães, observou-se que a maioria da população canina $(79 \%)$, nos dois grupos, não recebia a vacina polivalente, mas sim a anti-rábica ( $81 \%)$, veiculada pelo Centro de Controle de Zoonoses (CCZ) de Ilhéus.

Conforme relatos de moradores, muitos não sabiam da existência ou do significado da vacina polivalente, o qual foi explicado, então, durante a interpelação. Os animais vacinados recebiam vacinas oriundas de casas agropecuárias, as quais eram administradas em casa, por conta própria ou com ajuda de alguém da comunidade.

A vacinação inadequada dos cães pode gerar falhas na imunização dos animais, tanto por fatores intrínsecos ao animal, como por exemplo, a debilidade geral e má nutrição, como por falhas humanas, a exemplo de via de aplicação inadequada e desrespeito aos intervalos vacinais ${ }^{25}$.

Ressalta-se, ainda que, conforme relatos, a área de estudo possui uma população de ratos e camundongos, caçados com freqüência pelos cães locais, potencializando o risco de ocorrência de casos de leptospirose.

Lages et al., 2007, num estudo com cães de áreas periféricas, encontraram apenas $3,7 \%$ dos cães vacinados contra doenças infectocontagiosas $^{26}$. Lages, 2009, afirma que "o poder aquisitivo é um fator relevante na administração dessas vacinas"17.

Quanto ao acompanhamento veterinário dos cães, apenas 7\% dos animais o recebiam. Este fato pode dever-se ao baixo poder aquisitivo da comunidade, onde $41,6 \%$ dos domicílios apresentaram a renda média de até um salário mínimo. Lages, 2009, num estudo da população canina do Município de Jabuticabal, observou uma associação significativa entre a 
HARVEY, T.V., CAMPOS JÚNIOR, D.A. e CARDOSO, T.P. Estudo descritivo da população rural canina da Vila Juerana, Distrito de Aritaguá, Município de Ilhéus-BA, 2012. PUBVET, Londrina, V. 7, N. 1, Ed. 224, Art. 1485, 2013.

população canina de área com melhores índices socioeconômicos e o acompanhamento regular dos cães por veterinários ${ }^{19}$.

Nesta comunidade, $59,7 \%$ da população humana tinha de 0 a 30 anos, $48,3 \%$ eram analfabetos ou indivíduos com 10 grau incompleto, $37 \%$ eram desempregados e não tinham atividade econômica. Tais dados podem ter associação com o manejo deficiente destes animais, conforme foi relatado por alguns dos interpelados.

Salienta-se ainda que, $97,7 \%$ dos entrevistados declararam saber que os cães podem transmitir doenças ao homem, porém tinham conhecimento limitado sobre guarda responsável o sobre o modo de transmissão de doenças.

\section{CONCLUSÃO}

A razão cão:habitante apresentou-se elevada, em relação ao preconizado pelo Ministério da Saúde. O número elevado de cães semidomiciliados associado ao elevado número de fêmeas na Vila e seu manejo reprodutivo inaquedado viabilizam um crescimento populacional descontrolado indicando a necessidade da implantação de programas de controle populacional, nesta área. A baixa renda e o baixo nível de escolaridade dos proprietários dos cães foram influentes na qualidade do manejo sanitário e nutricional dispensado aos cães, porém não foram fatores determinantes para a aquisição destes animais. O conhecimento e a aplicação dos princípios de guarda responsável apresentaram-se limitados, indicando a necessidade do desenvolvimento de programas educativos na comunidade, no que diz respeito à guarda responsável, zoonoses e saúde ambiental, por parte do Serviço Público de Saúde. 


\section{REFERÊNCIAS BIBLIOGRÁFICAS}

1. Reichmann MLAB, Figueiredo ACC, Pinto HBF, Nunes VFP. Controle de populações de animais de estimação. In: Instituto Pasteur. Manual Técnico do Instituto Pasteur 6. São Paulo; 2000.

2. Vieira AML, Almeida AB, Magnabosco C, Ferreira JCP, Carvalho JLB, Gomes LH et al. Programa de controle de populações de cães e gatos do estado de São Paulo. Boletim Epidemiológico Paulista. 2006;3 Suppl 5.

3. Heukelbach J, Oliveira FAZ, Feldmeier H. Ectoparasitoses e saúde pública no Brasil:desafios para controle. Cad Saúde Pública. 2003;19(5):1535-1540.

4. Fonseca EOL, Teixeira MG, Barreto ML, Carmo EH, Costa MCN. Prevalência e fatores associados às geo-helmintíases em crianças residentes em municípios com baixo IDH no Norte e Nordeste brasileiros. Cad Saúde Pública. 2012; 26(1):143-152.

5. Matos MR, Alves MCGP, Reichmann MLAB, Dominguez MHS. Técnica Pasteur São Paulo para dimensionamento de população canina. Cad Saúde Pública. 2002;18(5):1423-8..

6. Soto FRM, Ferreira F, Pinheiro SR, Nogari F, Risseto MR, Souza O, Amaku M. Dinâmica populacional canina no Município de Ibiúna-SP: estudo retrospectivo. Braz J Vet Res Anim Sci. 2006;43(2):178-185.

7. Reece JF. Dogs and dog control in developing countries. In: The state of the animals: III. Extraído de [http://www.humanesociety.org/assets/pdfs/hsp/SOA_3-2005_Chap5.pdf] acesso em [02 de novembro de 2011].

8. Magnabosco C. População domiciliada de cães e gatos em São Paulo: perfil obtido através de um inquérito domiciliar multicêntrico [Dissertação]. São Paulo (SP):Universidade de São Paulo;2006.

9. Ávila-Pires FD. Zoonoses: hospedeiros e reservatórios. Cad Saúde Pública. 1989;5(1):8297.

10. WHO.World Society for Protection of Animals. Guidelines for the dog population management. Geneva: World Health Organization; 1990.

11. Brasil. Ministério da Saúde. Secretaria de Vigilância em Saúde. Departamento de Vigilância Epidemiológica. Doenças infecciosas e parasitárias: guia de bolso. 6a ed. Brasília; 2006.

12. Mascarenhas MTVL, Cerqueira RB, Penelucc T, Cardim LL, Brito VS, Silva MMN, Bittencourt TCBSC, Bavia ME. Geotecnologias na análise da população canina para o controle da raiva, considerando fatores socioeconômicos e demográficos. Município de Lauro de Freitas (BA) 1999-2004. Rev baiana saúde pública. 2009 Jul-Set;33(3):323-335.

13. Boni V, Quaresma SJ. Aprendendo a entrevistar: como fazer entrevistas em ciências sociais. Revista Eletrônica dos Pós-Graduandos em sociologia Política da UFSC. 1991;2(1):6880. .

14. Domingos, IH, Rigo L, Honer MR. Perfil das populações canina e felina do Município de Campo Grande, MS. Ensaios e Ciência. 2007 Abr;11(1):97-103. 
15. WHO - World Health Organization/WSPA - World Society for Protection of Animals. Expert Committee on Rabies: Eight Report. Geneva; 1992.

16. Butler JRA, Bingham J. Demography and dog human relationships of the dog population in Zimbabwean communal lands. Vet Rec. 2000;147:442-6.

17. Lages SLS. Avaliação da população de cães e gatos com proprietário, e do nível de conhecimento sobre a raiva e posse responsável em duas áreas contrastantes da cidade de Jaboticabal, São Paulo [Dissertação] São Paulo (SP): Universidade Estadual Paulista; 2009.

18. Brasil. Ministério da Saúde. Fundação Nacional de Saúde. Encontro Nacional dos Coordenadores de Zoonoses. Relatório Anual. Brasília (DF); 2002.

19. Geffray L, Paris C. Risques infectieux des animaux de compagnie. Med Mal Infec. 2001;31 Suppl 2:S126-142.

20. Morrison G. Zoonotic infections from pets. Postgrad Med. 2001; 110(1):24-34.

21. Burki T. The global fight against rabies. The Lancet. 2008;372(9644):1135-6.

22. Thornton GW. The welfare of excess animals: Status and needs. J Am Vet Med Assoc. $1992 ; 200(5): 660$.

23. Acha PN, Szyfres B. Zoonosis y enfermedades transmisibles communes al hombre y a los animals. 3a. . ed. Washington:Organizacion Panamericana de la Salud; 2003.

24. Rey L. Bases da parasitologia médica. Rio de Janeiro:Guanabara Koogan; 1992. p.349.

25. Andrade SF. Manual de Terapêutica Veterinária. 2ª̣. ed. São Paulo:Roca; 2002, p. 604-5.

26. Lages SLS, Nunes JOR, Frias DFR, Grupo Pet, XVIV Turma de Alunos do Curso de Medicina Veterinária da FCAVJ, Carvalho AAB. Avaliação do nível de conhecimento da população de bairros periféricos do Município de Jaboticabal, São Paulo, sobre posse responsável de animais de estimação. In: Anais do Congresso Nacional de Saúde Pública Veterinária. Fortaleza, Ceará; 2007. p. 91. 